\title{
Influence of Mechanical Scarification and Gibberellic Acid on Seed Germination and Seedling Performance in Pinus gerardiana Wall
}

\author{
Lokinder Sharma ${ }^{1}$, B. Madhusudhana Reddy ${ }^{1,2 *}$, Moumita Chatterjee ${ }^{2}$, \\ Salil Dhawan ${ }^{1}$ and Vinayak Pai ${ }^{2}$
}

${ }^{1}$ Forest Research Institute Deemed to be University, Dehradun, India

${ }^{2}$ Institute of Wood Science and Technology, Bengaluru, India

*Corresponding author

\author{
A B S T R A C T
}

\section{Keywords}

Pinus gerardiana, Chilgoza,

Germination,

Gibberellic acid,

Mechanical

scarification, Pre-

sowing treatments,

Vigour

Article Info

Accepted:

12 March 2020

Available Online:

10 April 2020
Pinus gerardiana is commonly called "Chilgoza Pine" which yields small edible seeds. The pine is a vital ecological and economic forestry species having restricted distribution in India. It's mostly found in two districts of Himachal Pradesh. It's been observed that the natural regeneration of the species is extremely poor or entirely lacking. This species has erratic and infrequent seed years and dormancy related problems that also reduce the regeneration process in natural habitats. Therefore, different treatments viz. Mechanical scarification, Gibberellic acid (100ppm) and combination of both, where the soaking period is kept 24hours and incubation temperature is kept $25^{\circ} \mathrm{C} \pm 1{ }^{\circ} \mathrm{C}$. The seeds were counted as germinated when radicle was a minimum of two $\mathrm{mm}$ long. The effect of presowing treatments on various germination parameters (Germination \%, Germination energy, mean daily germination, Peak value, Germination value, Germination index) was calculated and interpreted. After this, germinated seeds were put in root trainers and allowed to grow within the net house. After the establishment of seedlings various seedling assessment parameters (collar diameter, root-shoot length, number of needles) were measured properly for every treatment. Seed Vigour Index was also calculated separately. This study identified $\mathrm{T}_{4}$ (Mechanical Scarification $+100 \mathrm{ppm}$ Gibberellic acid) treatment as the best treatment for enhancing germination and seed vigour.

\section{Introduction}

Pinus gerardiana Wall is a small to a moderate-sized evergreen tree, varying from 2 to $4 \mathrm{~m}$ in girth and 17 to $27 \mathrm{~m}$ in height (Bhattacharrya, 1988). Branches somewhat ascending and usually not whorled. The bark is thin, grey, exfoliating in irregular thin flakes which leave shallow depressions.
Leaves needle-like, dark green and exists in clusters of three. Chilgoza seed is cylindrical, pointed, dark brown, with rudimentary wings, $2-2.5 \mathrm{~cm}$ long, endosperm oily and edible (Luna, 2008). The species has been described as the "Champion of Rocky Mountains" because it grows under extremely rough site conditions and may withstand the extremes of cold climate and aridity. Chilgoza is found 
only within the inner arid valleys of the North-West Himalayas, where the rainfall is scanty but there's heavy snowfall, the total precipitation amounting between $370-750 \mathrm{~mm}$. It endures severe cold in winter, the summer temperature within its habitat seldom exceeds $37^{\circ} \mathrm{C}$ (Luna, 2008). This species is sparsely distributed in Himachal Pradesh, covering a complete area of about 2060 ha with most of the area falling in Kinnaur District (2040 ha) and a small portion (20 ha) in Chamba district of Himachal Pradesh (Troup, 1921). According to the IUCN list 2020, this species belongs to a Near-threatened category.

It's a really important species from an ecological and economical point of view. The species is found within the dry temperate region which is extremely fragile, where landslide and erosion is a big problem during the rainy season. The tree is extremely much adapted to the present region, thanks to its inherent capacity to grow on rough terrain, even on a bare rock which has shallow soil, this tree is named as the champion of rock.

The seeds and seed oil of the plant have medicinal properties; the seeds are used as anodyne and stimulant. The oil is additionally used against wounds and ulcers. It's the sole conifer species in North West Himalayas that gives edible Kernels/nuts rich in carbohydrate, fat, fiber and mineral matter. Being nutritious and delicious, the seeds have high demand in local, national and international markets and fetch excellent prices.

Due to these high-priced edible nuts, this tree is being overexploited. This overexploitation affects the regeneration of this tree, where every cone is taken away for profit maximization and nothing is left for natural regeneration. All these activities adequately affect the seed germination behavior and seed vigour of the species.
The study of Pinus gerardiana germination is important for several reasons. First, our knowledge regarding $P$. gerardiana germination is inadequate, so it's important to know the germination pattern within the species. Second, $P$. gerardiana is a dominant component of dry temperate forests; the reduction of area under species would adversely affect ecology and economy of the region (Urooj and Jabeen, 2015).

The area under species has declined from 2500 ha (Singh, 1992) to 2040 ha (Sharma et $a l ., 2010)$ in the Kinnaur region. Pine forests play a crucial ecological role in regulating rivers and streams that originate and flow in a particular region (Harmon et al., 1986; Bilby and Bisson, 1998), and P. gerardiana helps in watershed protection in Himalayas (Akbar et al., 2014).

Because of all these major ecological roles played by $P$. gerardiana in dry temperate forests of Himalayas, it is essential to know the functioning of processes within these forests systems. Third, the construction of hydroelectric projects and other development activities (Yadav, 2009) had led to reduction of species distribution which will adversely affect the ecology of the region (Sarkar, 2008); for future management of those forests, it is essential to get the basic knowledge about the germination of this species.

Pre-sowing seed treatments have attracted considerable attention in recent years due to its role in enhancing germination and subsequent growth of the seedling. Besides the long duration stratification process, efficient pre-sowing treatments envisaging the soaking of seeds for a few minutes to days in growth regulators or water have been tried to break dormancy. The study has the following objectives such as to find out the best presowing treatment for the germination and to 
assess the various growth characteristics of seedlings like collar diameter, number of leaves per seedling, root and shoot length to determine the Seed Vigour Index (S.V.I) for different treatments.

\section{Materials and Methods}

\section{Study area}

The present study was conducted in the seed technology laboratory, Silviculture Division and Central Nursery of Forest Research Institute, Dehradun, Uttarakhand, India. The study work started in February 2016 and completed until mid-May 2016. The seed source of $P$. gerardiana was Luj, Pangi Forest Division, Chamba, Himachal Pradesh, India (Fig. 1). The area lies between $33^{0} 7^{\prime} 37.60 \mathrm{~N}$ latitude and $76^{0} 20^{\prime} 1.9 \mathrm{E}$ longitude.

Champion and Seth (1968) recognize ten subtypes of the forest in the Pangi region. Out of those ten subtypes, one is Neoza Pine Forest comprises species Pinus geradiana, Cedrus deodara, Fraxinus floribunda, Celtis australis in the dry and rocky areas in Luj and Kanun Reserve forest. The elevation of the Pangi valley ranges from 2006 to $6168 \mathrm{~m}$ MSL (Kumar et al., 2014).

\section{Pre-sowing treatment}

The seed coat of $P$. gerardiana is slightly hard and impermeable which can prolong the germination period. So, it is necessary to offer pre-sowing treatment to these seeds. It's given with four different treatments with five replications each and CRD factorial design was adopted to see whether which treatment will give better germination. The treatments are as follows, $\mathrm{T}_{1}=$ Control (Water Soaking), $\mathrm{T}_{2}=$ Mechanical Scarification and Water Soaking, $\quad \mathrm{T}_{3}=\mathrm{GA}_{3}(100 \mathrm{ppm}), \quad \mathrm{T}_{4}=$ Mechanical Scarification and $\mathrm{GA}_{3}$ (100ppm). The Soaking period was 24 hours. The
Mechanical scarification is completed by fine sandpaper at an area opposite from the radicle initiation portion. The portion was rubbed until the megagametophyte was exposed.

\section{Seed germination test}

Seed germination study was conducted by taking 400 seeds and subjecting them to four treatments and each treatment has given five replications. The seeds were placed in Petri dishes and these kept in germinator having temperature $25^{\circ} \mathrm{C} \pm 1^{\circ} \mathrm{C}$ and humidity $100 \%$. Seeds were checked regularly and counted as germinated when radicle was a minimum of 2 $\mathrm{mm}$. Being a temperate species of high Himalaya testing period was kept as about 40 days.

\section{Germination percentage}

Germination $(\%)=\frac{\text { Number of seed germinated }}{\text { Total no. of seed kept for germination }} X 100$

\section{Germination energy (GE \%)}

Germination energy $(\%)=$

$\frac{\text { Number of seeds germinated up to the time of peak germination }}{\text { Total }} X 100$ Total number of seeds sown

Mean daily germination (MDG) was calculated as the cumulative germination percentage of seeds at the end of the test period divided by the number of days from sowing to the end of the test or total days. Peak value (PV) was calculated as the maximum mean daily germination reached at any time during the period of the test (Czabator, 1962). Germination index (GI) was calculated by dividing the total number of seed germinated at the end of the experiment by the time taken for $50 \%$ germination. Germination value $(\mathrm{GV})$ is the index combining speed and completeness of seed germination. Daily germination counts were recorded and calculated as per (Czabator, 1962). 
$\mathrm{GV}=\mathrm{PV} \times \mathrm{MD}$

Where, $\mathrm{PV}=$ Peak value of germination, $\mathrm{MDG}=$ Mean daily germination

\section{Analysis of variance (ANOVA)}

The statistical analysis of each parameter was carried out on mean value and the analysis of variance was performed. The effect of treatment was assessed periodically through germination and initial growth performance of the seedlings in laboratory and root trainers respectively. Five seedlings from each treatment were randomly selected and uprooted very carefully to estimate the seedling length (i.e. root and shoot length), number of needles and collar diameter. Data were statistically analyzed for studying the morphological growth variation for each treatment (Table 2).

\section{Seed vigour index (S.V.I)}

Seed vigour is an important quality parameter that needs to be assessed to supplement germination and viability tests to gain insight into the performance of a seed lot in the field. The Seed vigour index (S.V.I) is calculated by multiplying germination (\%) and seedling length. The seed lot showing the higher seed vigour index is considered to be more vigorous (Abdul-Baki and Anderson, 1973).

\section{Results and Discussion}

\section{Effect of pre-sowing treatments}

The data presented in Table 1 reveals that there is a significant difference between different pre-sowing treatments. The very best germination $(67.00 \%)$ was registered in $\mathrm{T}_{4}$ treatment, at temperature $25^{\circ} \mathrm{C} \pm 1{ }^{\circ} \mathrm{C}$ and soaking period $24 \mathrm{~h}$. In a comparison of $\mathrm{T}_{4}$ with $\mathrm{T}_{1}, \mathrm{~T}_{2}$ and $\mathrm{T}_{3}$ treatment, the mean difference between $\mathrm{T}_{4}$ and $\mathrm{T}_{1}, \mathrm{~T}_{4}$ and $\mathrm{T}_{2}$, and $\mathrm{T} 4$ and $\mathrm{T}_{3}$ is $43 \%, 14 \%$, and $26 \%$ respectively. All these values are greater than the critical difference (CD) value (Fig. 2). This reveals that $\mathrm{T}_{4}$ (Mechanical scarification $+100 \mathrm{ppm}_{\mathrm{GA}}$ ) is significantly different from the rest of the treatments. Similar results were registered by Kumar et al. (2014), where germination was (73.84 and $62.71 \%$ ) when seeds were treated with Gibberellic acid concentration $75 \mathrm{ppm}$ and $150 \mathrm{ppm}$ respectively at temperature $25^{\circ} \mathrm{C}$ and soaking period $24 \mathrm{~h}$.

Germination energy (GE) (\%) of seeds of $\mathrm{T}_{4}$ (Mechanical scarification $+100 \mathrm{ppm} \mathrm{GA}_{3}$ ) treatment exhibit the highest germination energy $(59.00 \%)$. However, this was followed by $\mathrm{T}_{2}$ (Mechanical Scarification + Water) and $\mathrm{T}_{3} \quad\left(100 \mathrm{ppmGA}_{3}\right) \quad(46.00 \%$ and $32.00 \%$ respectively) treatments in descending order. Minimum germination energy $(19.00 \%)$ was, however, observed in $\mathrm{T}_{1}$ (control) treatment. High germination with gibberellic acid treatment could be attributed to a rise in gibberellins in seeds during germination (Cetinbas and Koyunchu, 2006; Chen et al., 2008; Dhoran and Gudadhe, 2012). Germination value $(\mathrm{GV})$ of seeds which are mechanically scarified and then soaked in gibberellic acid was higher (3.70) than control (0.39) (Table 3).

The combined effect of scarification and $100 \mathrm{ppm}$ gibberellic acid resulted in an increase in $\mathrm{GV}$ of seeds than other treatment combinations. Gibberellic acid-treated seeds began germinating sooner and completed germination faster. It could probably be due to the facilitation of cytokinin penetration in the testa and neutralization of inhibitors present in the embryo, thus enabling the embryo to rupture the seed coat (Cetinbas and Koyuncu, 2006).

Seedling quality assessment is critical to ensure reforestation success. While height and collar diameter is that the commonest traits 
evaluated during the seedling quality assessment, above ground morphology is not an accurate predictor of performance after out-planting. Root system morphology status may provide a more accurate indication of seedling potential (Anthoney et al., 2005). In light of the above reference, various traits of seedling quality were measured and their mean value is mentioned in Table 4.

Maximum mean collar diameter $(2.36 \mathrm{~mm})$ was registered in $\mathrm{T}_{4}$ treatment, the maximum mean number of needles (14.60) was found in $\mathrm{T}_{2}$ treatment, maximum root and shoot length (6.9 and $7.7 \mathrm{~cm}$ respectively) was found in $\mathrm{T}_{4}$ treatment. Lowest seedling mean collar diameter, shoot length and number of needles $(2.07 \mathrm{~mm}, 6.9 \mathrm{~cm}$, and 11.80 respectively) were found in $T_{1}$ treatment. Whereas the lowest root length $(6.1 \mathrm{~cm})$ was found in $T_{3}$ treatment. Seed Vigour Index (S.V.I) was calculated by using the above-given formula.

The seed treatment showing the higher seed vigour index is considered to be more vigorous (Abdul-Baki and Anderson, 1973). Maximum S.V.I (978.20) was observed in $\mathrm{T}_{4}$ treatment, after that $T_{2}$ and $T_{3}$ (752.60 and 557.60 respectively) in descending order. Lowest S.V.I (321.60) was observed in $T_{1}$ treatment. Rubbing the basal portion of seed which exposes the megagametophyte resulted in the promotion of the final germination of $P$. gerardiana. Table 3 clearly shows that $\mathrm{T}_{4}$ and
$\mathrm{T}_{2}$ (Mechanically scarified) treatments show the highest germination as compared to $T_{3}$ andT $_{1}$ (non-scarified). The rate of final germination in intact seeds of $P$. gerardiana was very slow, however, a remarkable increase both in rate and final germination was observed when the seeds were imbibed after seed coat removal. The reason why this enhancement occurs is not fully understood.

The seed coat of $P$. gerardiana is thin and papery and readily permeable to water. Therefore, there is no possibility of it interfering with water uptake. It may act as a barrier to gaseous exchange in the first few days of imbibition when the seed is in the activation stage with increasing requirement of oxygen.

The possible role of seed coat as an obstacle for germination may be due to the presence of certain chemical inhibitors in the seed coat or it may act as a barrier against the leaching out of inhibitors present inside the seed. The evidence that pine seed coat has water-soluble germination inhibitors was presented by some workers in the seed coat of Pinus pinea, they suggested that those germination inhibitors were involved in the regulation of $P$. pinea seed germination (Martinez et al., 1978). In light of the possibilities discussed above, there is a need to further explore this aspect of $P$. gerardiana seeds (Fig. 3-10).

Table.1 Germination $\%$ of different treatments and replications

\begin{tabular}{|l|c|c|c|c|c|c|c|}
\hline Treatment & \multicolumn{4}{|c|}{ Replication } & Total & Germination \\
\cline { 1 - 6 } & $\mathbf{R}_{\mathbf{1}}$ & $\mathbf{R}_{\mathbf{2}}$ & $\mathbf{R}_{\mathbf{3}}$ & $\mathbf{R}_{\mathbf{4}}$ & $\mathbf{R}_{\mathbf{5}}$ & & \\
\hline $\mathbf{T}_{\mathbf{1}}$ (control) & 15 & 20 & 40 & 25 & 20 & 120 & 24 \\
\hline $\mathbf{T}_{\mathbf{2}}$ (Scarification + Water Soaking) & 65 & 50 & 45 & 55 & 50 & 265 & 53 \\
\hline $\mathbf{T}_{\mathbf{3}}(\mathbf{1 0 0 p p m ~ G A})$ & 35 & 40 & 25 & 60 & 45 & 205 & 41 \\
\hline $\mathbf{T}_{\mathbf{4}}$ (Scarification + 100ppm GA $\left.\mathbf{3}\right)$ & 75 & 55 & 70 & 75 & 60 & 335 & 67 \\
\hline Total & 190 & 165 & 180 & 215 & 175 & 925 & \\
\hline
\end{tabular}


Table.2 Analysis of Variance (ANOVA)

\begin{tabular}{|c|c|c|c|c|c|}
\hline $\begin{array}{c}\text { Source of } \\
\text { variation }\end{array}$ & df & SS & MSS & F calculated & $\mathbf{F}_{\text {tabulated }}$ \\
\hline Treatment & 3 & 4993.75 & 1664.58 & 16.64 & 3.24 \\
\hline Error & 16 & 1600.00 & 100.00 & & \\
\hline Total & 19 & 6593.75 & 347.03 & & \\
\hline
\end{tabular}

$\mathrm{CD}_{0.05}$

Critical difference for Germination $(\%)=13.39$

Table.3 Effect of Pre-sowing treatments on Germination Value, Mortality \%, Germination energy and Germination Index

\begin{tabular}{|l|c|c|c|c|}
\hline Treatment & $\begin{array}{c}\text { Germination } \\
\text { Value }\end{array}$ & Mortality \% & $\begin{array}{c}\text { Germination energy } \\
(\mathbf{G E} \%)\end{array}$ & $\begin{array}{c}\text { Germination } \\
\text { Index }\end{array}$ \\
\hline $\mathrm{T}_{1}$ & 0.39 & 76 & 19 & 1.09 \\
\hline $\mathrm{T}_{2}$ & 1.97 & 47 & 46 & 2.41 \\
\hline $\mathrm{T}_{3}$ & 1.07 & 59 & 32 & 1.64 \\
\hline $\mathrm{T}_{4}$ & 3.70 & 33 & 59 & 3.72 \\
\hline
\end{tabular}

Table.4 Mean value of seedlings growth characteristics and Seed Vigour Index

\begin{tabular}{|l|c|c|c|c|c|c|}
\hline Treatment & $\begin{array}{c}\text { Collar } \\
\text { Diameter } \\
(\mathbf{m m})\end{array}$ & $\begin{array}{c}\text { No. of } \\
\text { needles }\end{array}$ & $\begin{array}{c}\text { Root } \\
\text { Length } \\
(\mathbf{c m})\end{array}$ & $\begin{array}{c}\text { Shoot } \\
\text { Length } \\
(\mathbf{c m})\end{array}$ & $\begin{array}{c}\text { Seedling } \\
\text { Length } \\
(\mathbf{c m})\end{array}$ & S.V. I \\
\hline $\mathrm{T}_{1}$ & 2.07 & 11.80 & 6.5 & 6.9 & 13.4 & 321.60 \\
\hline $\mathrm{T}_{2}$ & 2.26 & 14.60 & 6.8 & 7.4 & 14.2 & 752.60 \\
\hline $\mathrm{T}_{3}$ & 2.11 & 12.20 & 6.1 & 7.5 & 13.6 & 557.60 \\
\hline $\mathrm{T}_{4}$ & 2.36 & 14.20 & 6.9 & 7.7 & 14.6 & 978.20 \\
\hline
\end{tabular}

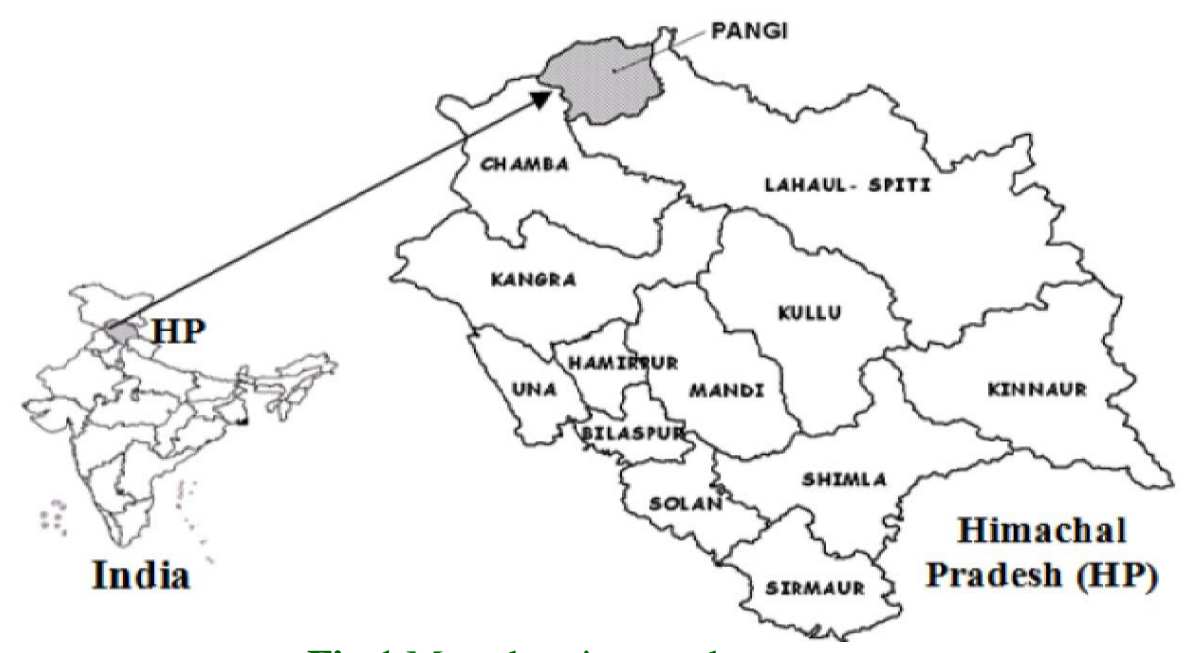

Fig.1 Map showing seed source area 


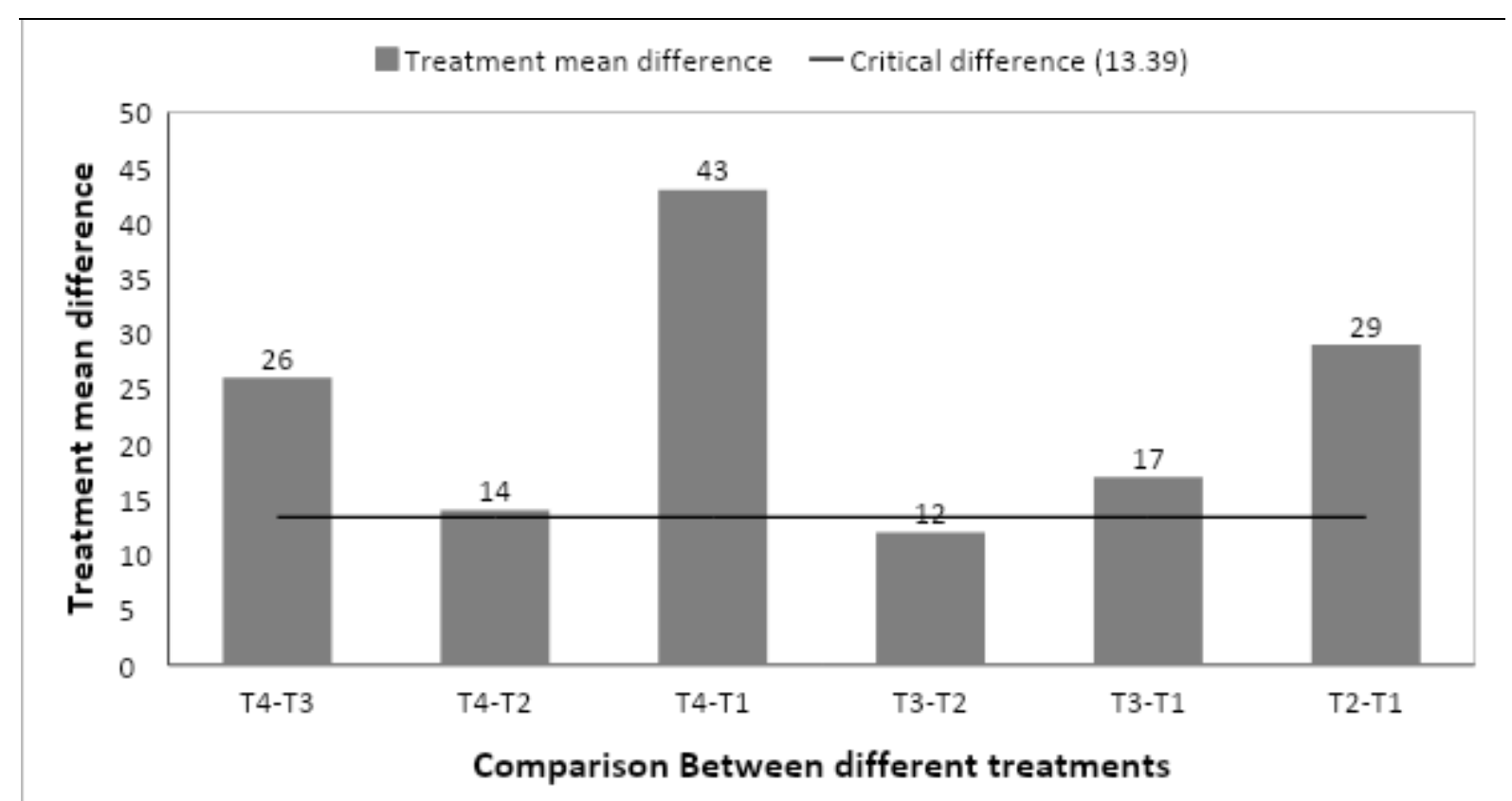

Fig.2 Significant difference between different treatments

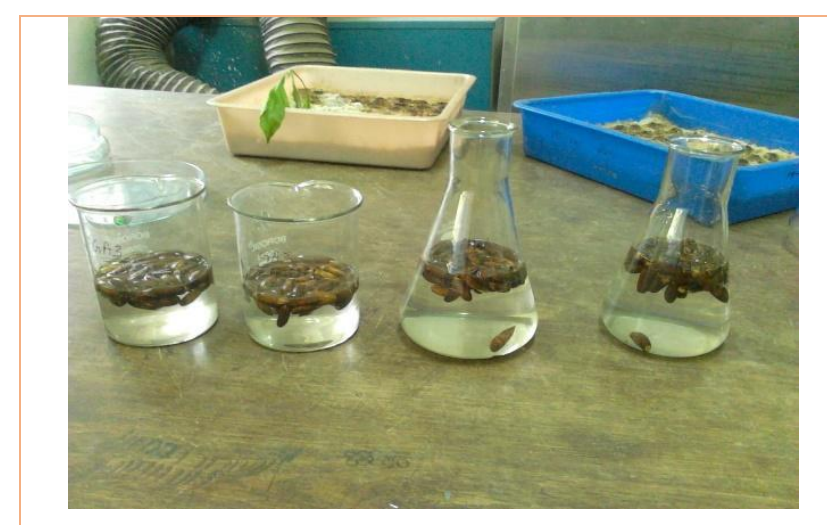

Fig.3 Different Treatments given to Seeds

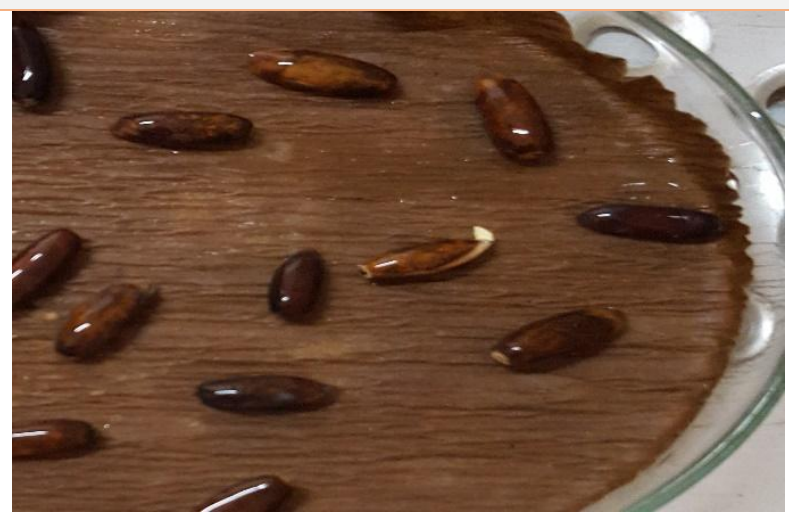

Fig.5 First sign of germination

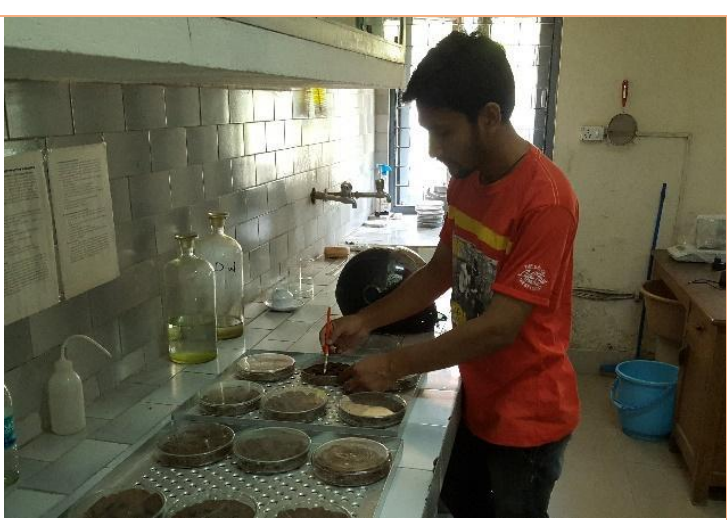

Fig.4 Cleaning of Seeds attacked by Fungus

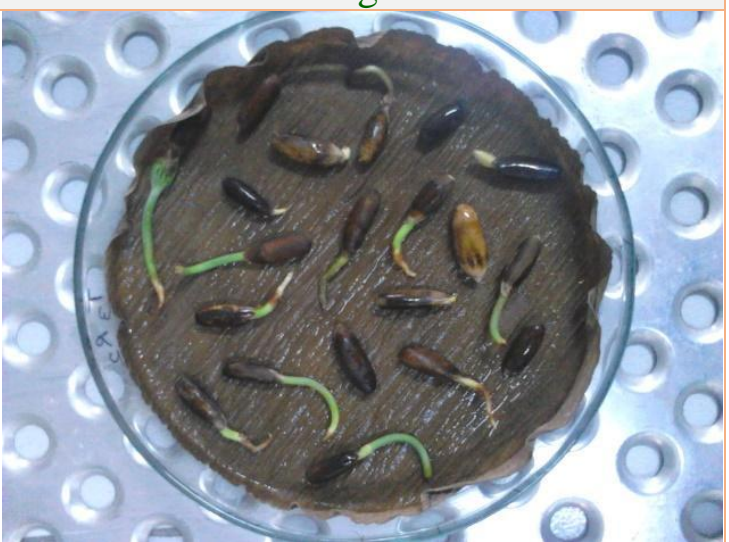

Fig.6 Germination at Full Capacity 


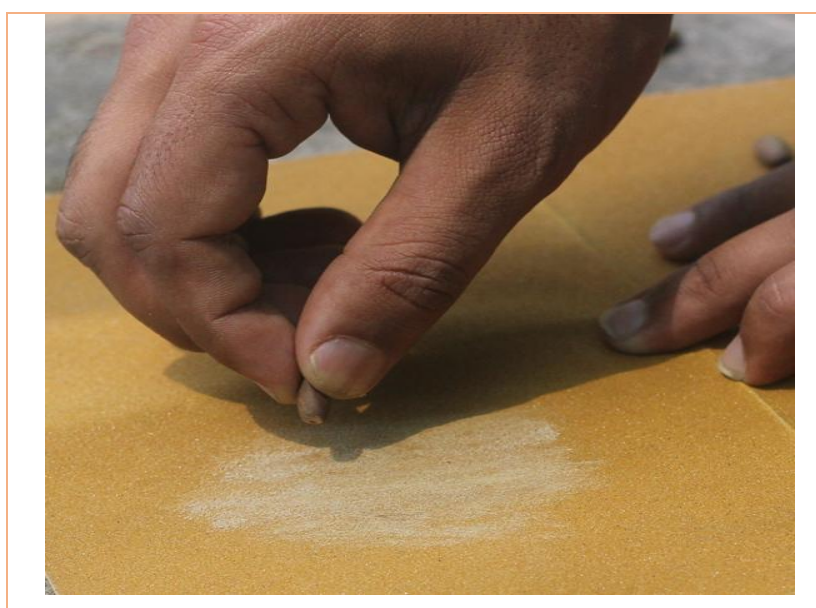

Fig.7 Mechanical Scarification

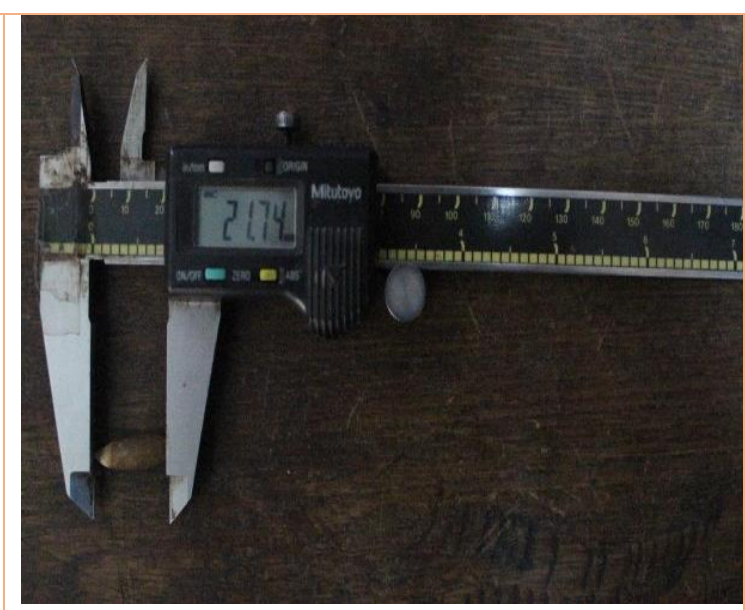

Fig.8 Measurement of Seed Traits

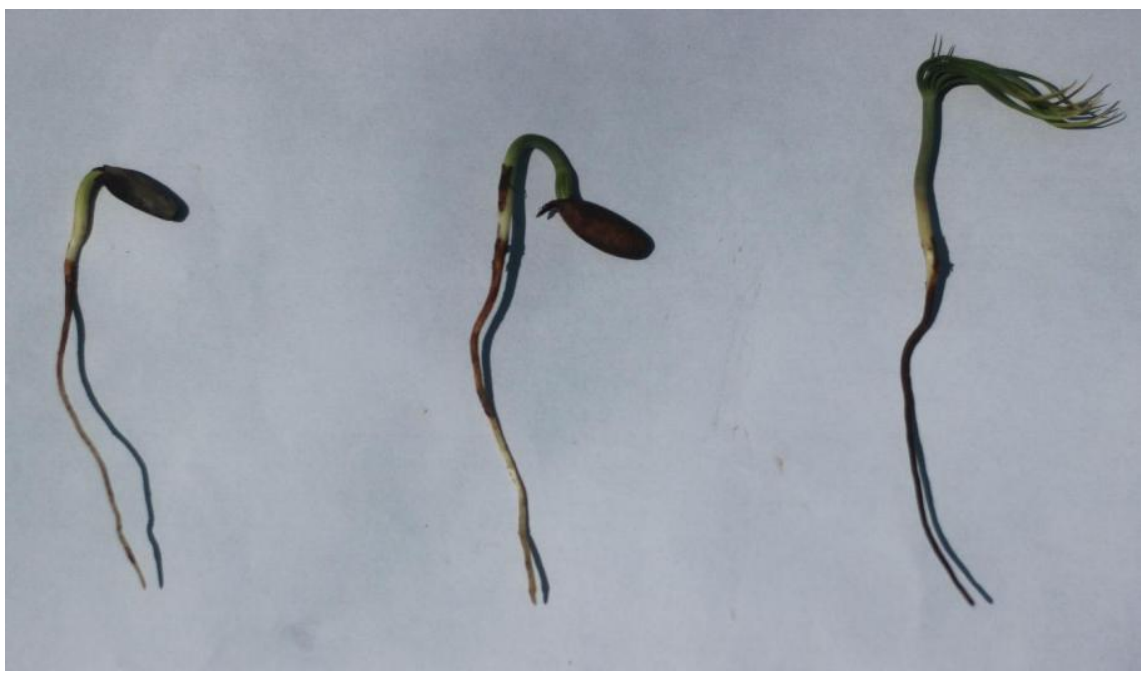

Fig.9

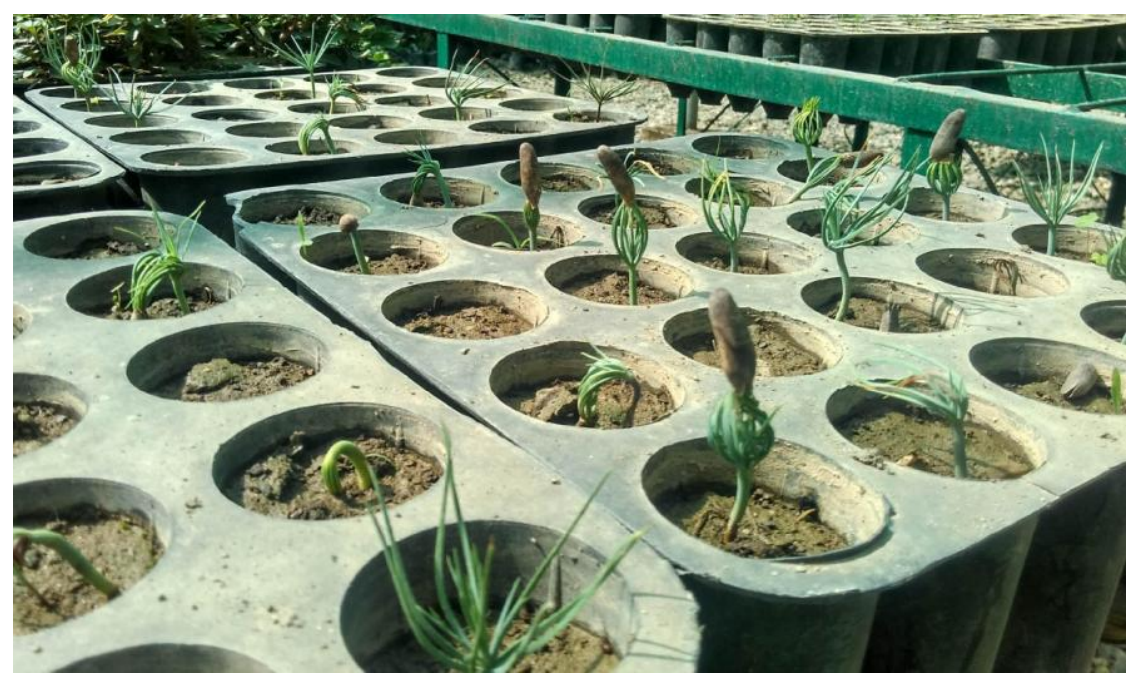

Fig.10 
The results of the study conclude that germination and seedling growth of $P$. gerardiana seeds depends on pre-sowing treatments. From the study, it is recommended that a combination of $\mathrm{T}_{4}(100$ ppm gibberellic acid + Mechanical scarification), $24 \mathrm{~h}$ soaking and $25^{\circ} \mathrm{C} \pm 1{ }^{\circ} \mathrm{C}$ incubation temperature is best for enhancing germination and seedling growth of Chilgoza pine.

As there is no significant difference between $\mathrm{T}_{2}$ (scarification + water soaking) and $\mathrm{T}_{3}$ (100ppm $\mathrm{GA}_{3}$ ), both these treatments are statistically the same. So, it is also recommended to prefer $\mathrm{T} 2$ (scarification + water soaking) over $\mathrm{T}_{3}\left(100 \mathrm{ppmGA}_{3}\right)$ because this will reduce the cost of production of Chilgoza seedlings in the nursery. The reason why this enhancement occurs in mechanically scarified seeds is not fully understood.

The possible reason may be a seed coat act as a barrier against the leaching out of inhibitors present inside the seed. However, extensive research on the effect of seed coat could further elucidate protocol for faster germination and seedling growth of $P$. gerardiana.

\section{References}

Abdul-Baki A. and Anderson J.J. (1973). Vigour determination in soyabean by multiple criteria crop sci.13:630-633. Study on seed dormancy of selected economic tropical forest species. Nig. J. Bot., 4: 115-125.

Akbar M, Khan H, Hussain A, Hyder S, Begum F, Khan M, Ali A, Hussain SA, Raza G, Khan SW, Abbas Q, Ali S (2014) Present status and future trend of chilgoza forest in Gharabad, district Diamer, Gilgit-Baltistan, Pakistan. J Biodivers Environ Sci 5(5): 253-261.

Anthoney S. Davis, Douglass F. Jacobs
(2005). Quantifying root system quality of nursery seedlings and relationship to out planting performance. Vol 30(2) pp. 295-311.

Bhattacharyya A, Lamarche $\mathrm{VC} \mathrm{Jr}$ and Telewski FW 1988. Dendrochronological reconnaissance of the conifers of northwest India. Tree-Ring Bulletin 48: 21-30.

Cetinbas, M., and Koyuncu, F. (2006). Improving germination responses of three congeneric cactus germination of Prunusavium L. seeds by gibberellic acid, potassium nitrate, and thiourea rarity. Horticultural Science, 3, 119123.

Champion H G and Seth S K. 1968. A Revised Survey of the Forest Types of India. Manager of Publication, Delhi-6. $511 \mathrm{p}$.

Chen, S. Y., Kuo, S. R., and Chien, C. T. (2008). Roles of gibberellins and abscisic acid in dormancy and germination of red bayberry (Myricarubra) seeds. Tree Physiology, 28(9), 1431-1439.

Czabator, F. J. (1962). Germination value: An index of combining speed and completeness of pine seed germination. Forest Science, 8, 386-396.

Dhoran, V. S., and Gudadhe, S. P. (2012). Effect of plant growth regulators on seed germination and seedling vigour in Asparagus sprengeri regel in. International Research Journal of Biological Sciences, 1(7), 6-10.

Harmon ME, Franklin JF, Swanson FJ, Sollins P, Gregory SV, Lattin JD, Anderson NH, Cline SP, Aumen NG, Sedell JR, Lienkaemper GW, Cromack KJ, Cummins KW(1986)Ecology of coarse woody debris in temperate ecosystems. Adv Ecol Res 15:133-302.

Kumar R., Shamet G. S., Mehta H., Alam N. M., Tomar J. M. S., Chaturvedi O.P., Khajuria N. (2014) Influence of 
gibberellic acid and temperature on seed germination in Chilgoza pine (Pinus gerardiana Wall.) Ind J Plant Physiol. 19(4):363-367.

Luna, R. K. (2008). Plantations Forestry in India (pp. 920-922). Dehradun: International book distributors.

Martiney-Honduvilla C. J, Santos-ruiz A. (1978). Germination inhibitors in Pinus seed coat. Vol.141, Issue 2, pp. 141144.

Saeed M, Thanos C A. (2006). The effect of seed coat removal on seed germination of $P$. gerardiana Wallich ex D. Don. Chilgoza pine. J. App. Em. Sc:1(3) 174177pp.

Sarkar R (2008) Accessibility: a boon or a dilemma: weighing outcomes in an ecologically fragile belt of the middle Himalayas. Proceeding of International
Conference on Transportation Systems, Central Building Research Institute, Roorkee, India, February, 10-12, 2008.

Sharma P, Sehgal RN, Anup R (2010) Natural regeneration of Pinus gerardiana in dry temperate forests of Kinnaur (Himachal Pradesh). Indian J For 33(4):511-518.

Singh NB (1992) Propagation, selection, and establishment of clonal seed orchard of chilgoza pine (Pinus gerardiana WALL.). The Indian Forester 118 (12): 901-908.

Troup R S. Silviculture of Indian Trees. Vol. III. Clredon Press, Oxford.

Urooj R, Jabeen A (2015) Present status of Pinus gerardiana Wall. in Pakistan: a review. Middle East J Bus 10(4):46-48.

Yadav RR (2009) Tree rings imprints of longterm changes in Western Himalayas. Indian J Biosci 34:699-707.

\section{How to cite this article:}

Lokinder Sharma, B. Madhusudhana Reddy, Moumita Chatterjee, Salil Dhawan and Vinayak Pai. 2020. Influence of Mechanical Scarification and Gibberellic Acid on Seed Germination and Seedling Performance in Pinus Gerardiana Wall. Int.J.Curr.Microbiol.App.Sci. 9(04): 1356-1365. doi: https://doi.org/10.20546/ijcmas.2020.904.161 